\title{
The Impact of Belt and Road Initiative in Cultivating International Students in Chinese Universities
}

\author{
Huang Ting $^{1^{*}} \quad$ Prasad Siba Borah $^{1} \quad$ Fen Yun $^{2} \quad$ Zhi Liangze $^{2}$ \\ 1.School of Management, Jiangsu University, Zhenjiang, China (212013) \\ 2.International Office, Jiangsu University, Zhenjiang, China (212013)
}

\begin{abstract}
China's Belt and Road Initiative (BRI), sometimes referred to as the "New Silk Road", is one of the most significant projects ever to be carried out. Introduced by President Xi Jinping in 2013, the wide range of development and investment from East Asia to Europe, and Africa. BRI provides support for the education of international students in China. The countries along the Belt and Road ("Belt and Road Countries") have different endowments in resources and complementary economies and there is great potential for linkages and common development between them. China will strengthen cooperation with Belt and Road countries by strengthening cooperation on policies, infrastructure, trade, and finance and people-to-people connectivity with them.China has a rich and deep historical and cultural heritage, unique academic cultural traditions and a social custom of great respect for teachers and teaching; in such a favorable policy, China will attract even more foreign students. More foreign students will not only help "spread the word" about China's rich and profound culture, but also promote colleges and universities and improve the use of the Belt and Road as a platform through which the culture of messengers and international talents can better understand and appreciate its culture. However, there is still a deep gap between the demands and availability, mainly due to the quality of communication. This study expands the main problems in the cultivation of international students by identifying the kind of cultural exchange needed for The Belt and Road construction, and then makes suggestions to improve the quality of cultural exchange in terms of Belt and Road Initiative.
\end{abstract}

Keywords: Cultivation Strategy; Chinese universities; international students; The Belt and Road Initiative

DOI: $10.7176 / \mathrm{EJBM} / 13-20-15$

Publication date:October $31^{\text {st }} 2021$

\section{I.Introduction}

In 2013, Chinese President Xi Jinping put forward the major initiatives of jointly building the Silk Road Economic Belt and the 21st-Century Maritime Silk Road (hereinafter referred to as "The Belt and Road Initiative") during his visits to Asian countries (Huang, 2016). The Belt and Road lines run through the continents of Asia, Europe and Africa, connecting the vibrant East Asia economic circle at one end and developed European economic circle at the other, and encompassing countries with huge potential for economic development. So many countries are along the lines with vast space, complex national conditions and a wide range of cooperation fields. Therefore, a large number of international talents with high professional quality, familiar with international laws and mastering multiple languages are urgently needed.

In the construction of the Belt and Road, international talents will be the leading role to promote the implementation of various tasks. It is a common and pressing task for universities to train professional talents as needed. More and more international students from The Belt and Road countries came to study in China. BRI helps integrate university and college education resources for international students to support development. Implementing BRI requires a large number of talented interdisciplinary staff and knowledgeable professionals with international rules. Because colleges and universities are important foundations for talent education, BIR not only provides a favorable platform on which universities can expand the entry scale for international students, but also provides an effective foundation for international student development, restructuring of foreign students education in China (Hurley, Morris, \& Portelance, 2019).

BRI also led on more opportunities that are educational for international students in Chinese colleges and universities. BRI supports and serves the development of international student education in China; it strengthens China's international status and its international influence. Figure 1 below shows the pathways of the 2017 undergraduates Sino-Foreign University where Xi'an Jiaotong-Liverpool University recorded the highest number. 
Figure 1

\section{Sino-Foreign University Undergraduates Intended Pathways}

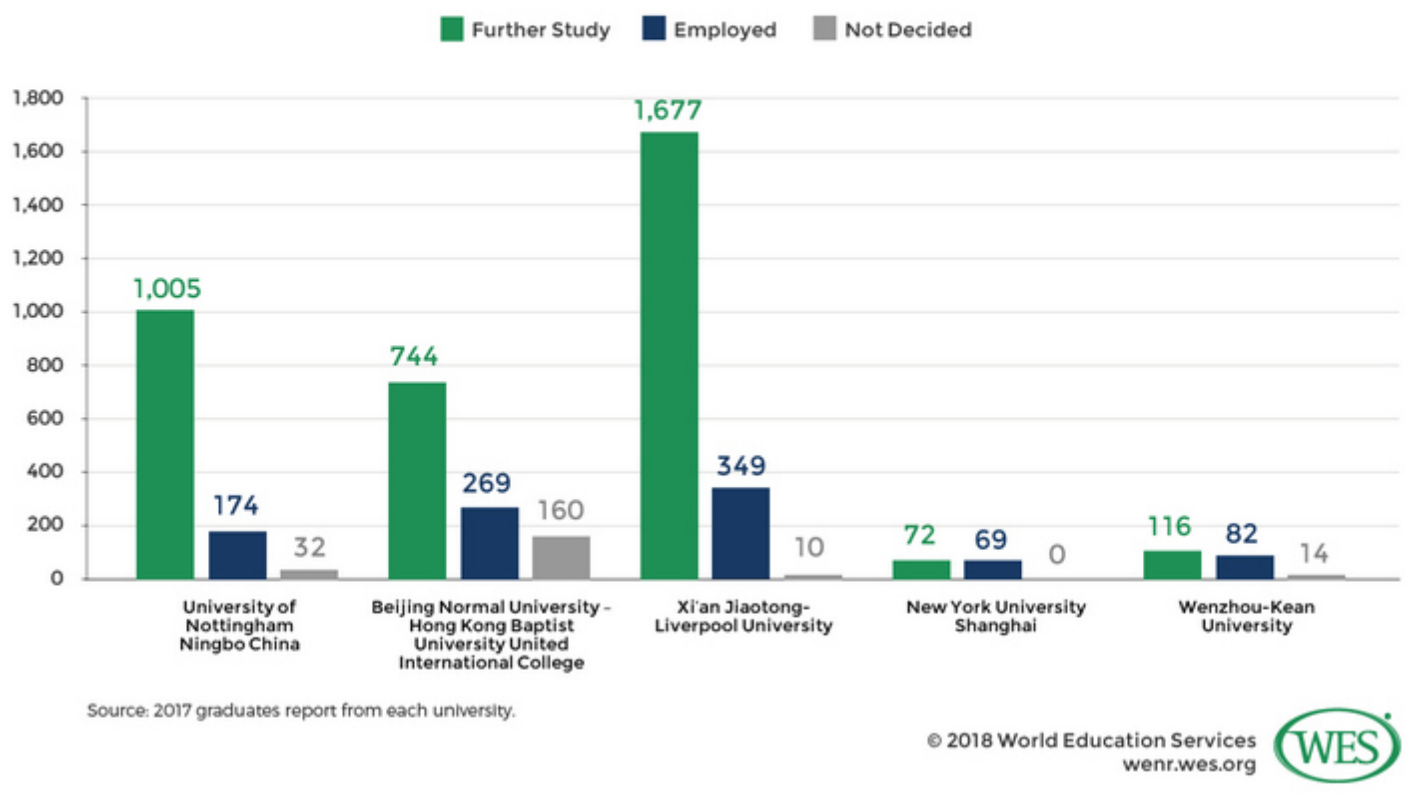

Sino-Foreign University Undergraduates Pathways

With the growing number of international students in China, the country plays an increasingly important role in the decision-making process in international affairs. In this context, more and more foreigners are eager to learn more about China. Meanwhile, there will be foreign students studying in China, of course under the influence of Chinese culture in their studies and daily life, and their feelings can be gradually expressed in their vision for a better world. At the same time, international students who come to study in China are sure to help spread the impact of Chinese education around the world. This study expands the main problems in the cultivation of international students by identifying the kind of cultural exchange needed for The Belt and Road construction, and then makes suggestions to improve the quality of cultural exchange in terms of Belt and Road Initiative.

\section{Literature Review}

Most Belt and Road countries are emerging economies and developing countries, which are generally in the rising stage of economic development and have different resource endowments (Rolland, 2019). The economies are highly complementary to each other and there is great potential and space for cooperation. There is a huge demand for high-quality talents in the Belt and Road construction. The specific characteristics of them are as follows:

\subsection{International Talents Adapt on the Field of Policy Coordination}

In 2010, China launched a national approach and long-term talent development plan (2010-2020) and designed 12 major talent projects. Using the basic approach and statistical analysis, JianQuan, Xuan, HongWei, and YingJie (2019) compared goals with actual implementation and accomplishment, although most talents are absolute. The following effects: implementation of documents, constitutional conflict between different sectors, lack of classification system, etc., make the policy difficult to implement and lack of persistency and stability. International talents needed for policy coordination are mainly high-level leadership talents, which are mainly involved in the fields such as diplomacy, international organization, high-level visits and regional cooperation planning. Therefore, international high-quality talents who understand multiple languages, are good at diplomatic negotiation and know well about specific professional fields are needed. Policy coordination is the foundation and the key to win-win cooperation (T. Song, Liu, Liu, \& Wuzhati, 2019).

Zheng (2019) described the culture of international talent "on board", a practice conducted in Hebei in the bidirectional opening of higher education, which aims to cultivate international management talents who understand international law, master economic management skills. In the context of globalization, Innovation skills, intercultural skills, practical skills and a good understanding of foreign languages can be applied in working environment and adopt rules of international business in companies and institutions (Ma, 2019). According to Kirby and Van der Wende (2019) China publicly seeks to lead globalization by rapidly expanding its higher education and research systems and actively collaborating with academic partners along the New Silk Roads to 
attract (back) talent. However, under what conditions? what definitions and on the basis of what values? In addition, what difference will the "New Silk Road" make in the global education landscape?

With the development of the Free Trade Area and Belt and Road, mainstream local universities need to promote international talent. Now there are still problems with the formation of International talent for applied specializations in mainstream local universities, such as: To this end, the local mainstream school should be innovative (A. Peters et al., 2020). For example, through careful selection of objects for cooperative school management to promote the integration of educational and cultural concepts, to follow the path of international talent promotion based on business pedagogical orientation, scientific talent evaluation system. It would thus promote high-quality applied international talent for the external development of the local economy (Zhu \& Chen, 2019).

\subsection{International Talents Adapt on the Field of Facilities Connectivity}

China and the other Belt and Road countries have carried out a large number of cooperation in the fields of ports, highways, electric power, aviation, communications, etc., effectively improving the level of infrastructure construction in these countries. The skilled, innovative and advanced talents represented by civil engineers, traffic engineers, information engineers and mechanical engineers will be the backbone force to promote the construction.

M. Li and Zhu (2019) briefly explained the global dimension by focusing in particular on the criterion of "international talent" and the requirements of the internationalization of higher education, and dealt with the management of the foreign policy of universities as they play a crucial role in promoting the internationalization of education, research and governance. Which can be seen as a key element in the development of the global dimension of innovation in higher education for foreigners. H. Song, Varma, and Zhang Zhang (2021) in their study confirmed that motivational cultural intelligence has a positive and significant effect on cultural adaptation: adaptation to work, general adaptation or talent. Their study helped us understand the field of global talent management and the importance of motivational cultural intelligence and cultural distance for expat talent.

During the gradual integration of the world economy, China launched the Belt and Road Initiative. This initiative creates both opportunities and challenges for foreign language teaching in China at the university level. There is currently a growing need for small linguistic and intercultural talents. Some of the challenges of foreign language teaching and actions taken by governments, colleges, universities and teachers based on the Belt and Road initiative were faced. The teaching of foreign languages must accompany current national developments and create a promising future (Xinchun, Weibin, \& Yanli, 2020). At present, China's ports have established shipping links with over 600 major ports in more than 200 countries in the world, and the index of maritime connectivity has ranked first in the world. Maritime transport services have covered all Belt and Road coastal countries (Maçães, 2019). In 2018, 6,300 China-Europe International Business (CEIBS) trains were launched, an increase of $72 \%$ over last year. By the end of 2018, the number of CEIBS trains had reached 13,000, with 59 Chinese cities running 65 routes and reaching 49 cities in 15 European countries (C. Li, 2021). Compared with highly developed Western Europe, Central \& Eastern European countries, Asian \& African countries are in strong demands for infrastructure construction.

\subsection{International Talents Adapt on the Field of Unimpeded Trade}

According to Zhang (2021), free trade "is an important part of the" One Belt and One Road "initiative. The digital economy is closely linked to government policies, infrastructure connectivity, free trade, financial integration and person-to-person connectivity. As One Belt and One Road suggest The rapid development of the digital economy has become a new driving force to effectively reduce the cost of trade and accelerate the free trade process, the main contents of the promotion of the construction of the belt and roads from a combination of text search. From the perspective of the BRI, Gholizadeh, Saneinia, and Zhou (2019) in their study, which had the backdrop of the development of international trade, illustrates the importance of the BRI for the exchange of high-speed railway (HSR) talent between China and the countries along the Silk Road. Considering how talent exchanges with other countries can be done along the way, this article provides relevant tips to expand international talent exchange and promotion in China to meet new challenges, and needs talent development around the world and strengthen international cooperation and cultural exchanges with countries along the way.

Smooth trade needs international talents, who have economic management skills, international communication skills and multinational enterprises working experience. From the data of China's trade volume along the past six years, the proportion of total volume is still small, and due to factors such as poor macroeconomic conditions, China's merchandise trade volume has had trouble. One of the important reasons is the shortage of international talents who can accelerate the cooperation, and promote the development of industrial clusters. That puts forward higher requirements for international economic and trade talents (Zhu \& Chen, 2019). Organizations have always relied on talent to improve their performance. However, as the war for talents intensifies, the competition for talented employees is unprecedented. Key to success is encouraging the widespread adoption of a talent management mentality and leveraging the second generation of the Internet. The purpose of this document 
is to describe the methods companies can use to attract and retain talent in order to outperform the competition (A. Peters et al., 2020).

China and The Belt and Road countries have generally maintained a growth trend in trade scale. From 2013 to 2017, the total import and export volume between China and the "Belt and Road" countries reached 69,756.23 billion US dollars, and the growth rate of trade with related countries was higher than that of China's international trade (Hillman, 2018). In 2017, the total import and export volume between China and The Belt and Road countries reached $\$ 1,440.32$ billion, a year-on-year growth of $13.5 \%, 5.9$ percentage points higher than China's overall foreign trade growth. The top 10 countries in the trade volume are Korea, Vietnam, Malaysia, India, Russia, Thailand, Singapore, Indonesia, the Philippines and Saudi Arabia, accounting for $68.9 \%$ of the total trade volume between China and The Belt and Road countries (Wang \& Xin, 2020).

\section{III.Methodology and Research Questions}

\subsection{Methodology}

In order to conduct this study, the main method of research employed was a comprehensive literature review. These data were based on the theoretical framework of existing scholarly work and public information from government website. The study proposes statements to determine strategy of international students' cultivation of Chinese universities in the view of The Belt and Road Initiative. In addition, analyzes and finds answers to these statements. According to the results, the work conducts discussion, mainly including how the following aspects limit the qualities of international students' cultivation: such as relaxation of enrollment requirements, to be improved cultivation approaches and management ability, limited professional courses and disciplines, and dramatic impact of COVID-19 pandemic. Although there are many strategies will promote international students studying in China, this study is mainly involved the followings: strict control of enrollment, improve training plan design, faculty staff construction, develop curriculum system, enhance management \& service capacity, and adapt to new changes brought about by the pandemic.

\subsection{Research Questions}

The BRI is not just a one-sided "introduction". Currently, China's "entry" and "exit" education is classified and managed. Sino-foreign vocational training is a combination of "in" and "out". This is an important measure to promote the development of open mutual education in China. From the point of view of the practice of Sinoforeign vocational training, most of the cooperative education universities for the training of international personnel have a different status, local colleges and universities are becoming an important stake in international education (Zheng, 2019). In order to validate our study, we based on the following questions:

Q1: What are the relevant field of studies international students under the BRI can enroll to achieve a successful corporation in future?

Q2: What are the specific problems encountered by Chinese universities in cultivating international students during their studies?

Q3: What are the appropriate cultivation strategies Chinese universities can adopt for their international students?

\section{IV.Analysis on the Status Quo of International Students Studying in China}

China has been the world's top five destination countries for international students with USA, the UK, Australia and Canada since 2013. The reasons are as follows: (1) The level of higher education in China is rising rapidly, and many universities come to the world-class level in the general rankings and/or the discipline performance. (2) Central government gives strong supports, the Department of International Cooperation and Exchange, Ministry of Education continuously improved the system of laws and regulations, the support policy chain of studying in China. That is the quality assurance system. (3) Benefitting being the world's second-largest economy, China has the capacity to offer enough scholarships in order to attract international students, such as the China Scholarship Council's work ${ }^{[1]}$.

Since the Ministry of Education, China release statistics on international students studying in China until 2018 , this paper's data of the whole country and province is as of 2018 . According to the 2018 data (all of the following data do not include Hong Kong, Macao and Taiwan) from Ministry of Education, China, a total of 492,185 international students from 196 countries and regions studied in 1,004 universities and colleges in 31 provinces (autonomous regions and cities) of China. It showed an increase of 3,013 over 2017 and the growth ratio was $0.62 \%$. Date among which from countries along the Belt and Road was 317,200, accounting for $64.85 \%$ and the growth ratio was $11.58 \%$, which was higher than the average growth ratio comparing with $2017^{[2]}$.

\subsection{According to Continents}

The total number of Asian students was 295,043, the total number of African students was 81,562, the total number of European students was 73,618, the total number of American students was 35,733, and the total number of Oceanian students was 6,229. The Belt and Road lines cross the continents of Asia, Europe and Africa and 
welcome the large number of students studying in Oceania in China. As mentioned, the Belt and Road lines run through the continents of Asia, Europe and Africa, fitting the large numbers of students studying in China. These figures suggest that BRI can help Chinese universities effectively integrate international education resources and can highlight their major disciplines (Liu, Zhang, \& Xiong, 2020). As mentioned, the Belt and Road lines run through the continents of Asia, Europe and Africa, fitting the large numbers of students studying in China.

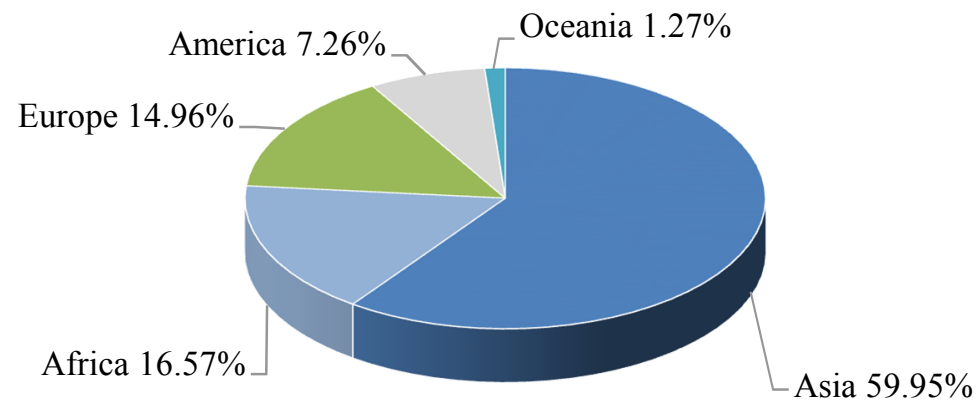

Figure 2 Percentage of international students coming to China from different continents

From Figure 2, we can identify that the Asian continent constitute one of the major leading continent in terms of international flow of students in China from neighboring countries. These shows that more countries under the BRI are eager to learn from China and adopt their development policies.

\subsection{According to Countries}

The top 15 resource foreign countries were South Korea, Thailand, Pakistan, India, the United States, Russia, Indonesia, Laos, Japan, Kazakhstan, Vietnam, Bangladesh, France, Mongolia and Malaysia. Among them, 80\% are Belt \& Road countries, and Thailand, Pakistan, India, Russia, Indonesia; Laos, Kazakhstan, Vietnam, Bangladesh, Mongolia are the top 10 countries along the Belt and Road. Figure 3 below show the number of international students from various countries enrolling in Chinese universities.

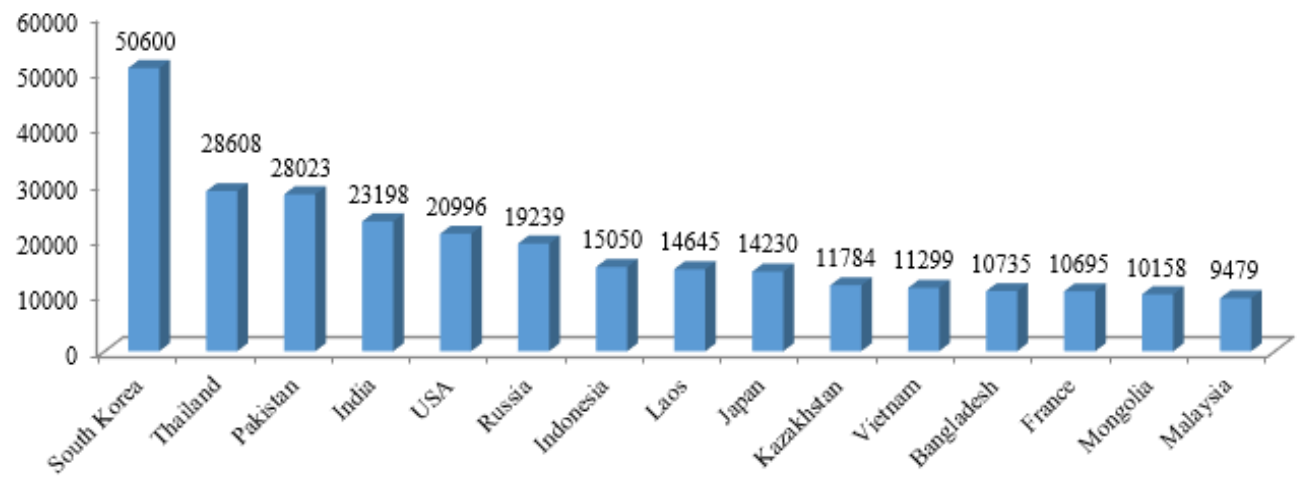

Figure 3 Number of international students coming to China from different countries

Despite the Covid-19 pandemic, Chinese universities have enroll many international students where they are enrolled in an online program. Chinese universities are promoting themselves very well and are getting more students all over the globe.

\subsection{According to Provinces}

The top 10 provincial administrative regions were Beijing, Shanghai, Jiangsu, Zhejiang, Liaoning, Tianjin, Guangdong, Hubei, Yunnan and Shandong. In addition, the provinces (autonomous regions and cities) with more than 10,000 international students in 2018 also include 15,217 people in Guangxi, 13,990 in Sichuan, 13,429 in Heilongjiang, 12,919 in Shaanxi, and 10,340 in Fujian. Among them, 73.33\% are the key provincial areas under the Belt and Road Initiative. 


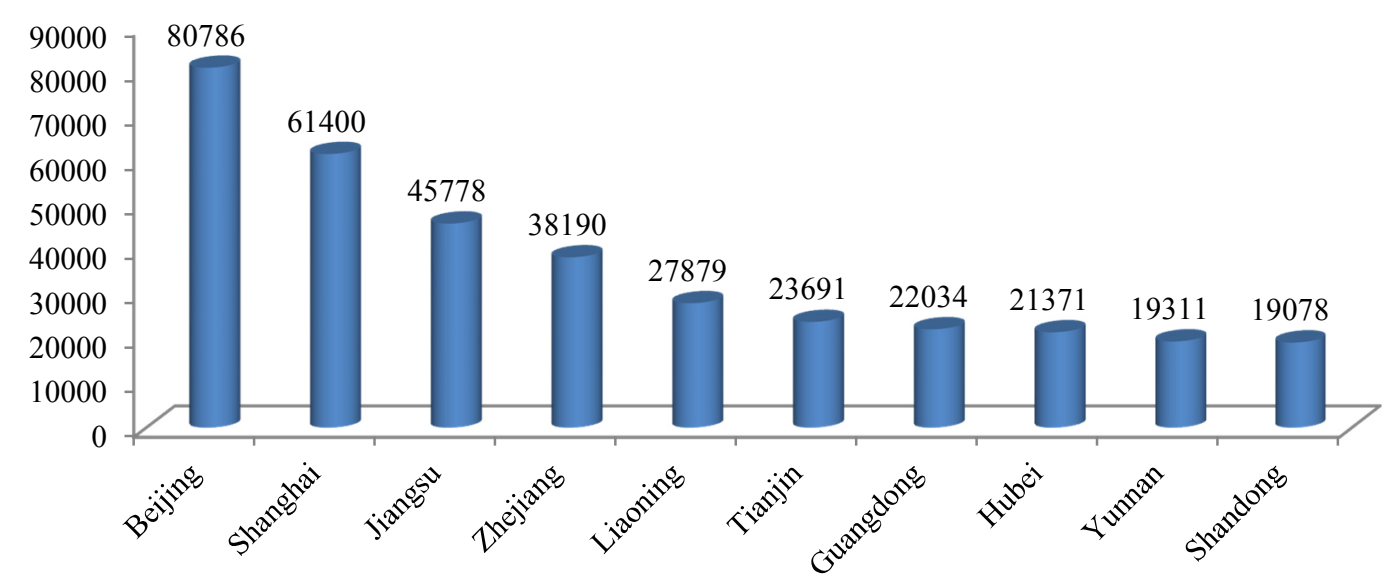

Figure 4 Number of international students coming to China in different provincial administrative regions

\subsection{According to the Student Categories}

The number of international students who received degree education in China is 258,122 , accounting for $52.44 \%$ of the total students coming to China, including 173,060 bachelor students, 59,444 master students and 25,618 doctoral students. That showed an increase of 16,579 from 2017 with ratio $6.86 \%$. On the other hand, there were 234,063 non-academic students studying in China, accounting for $47.56 \%$.

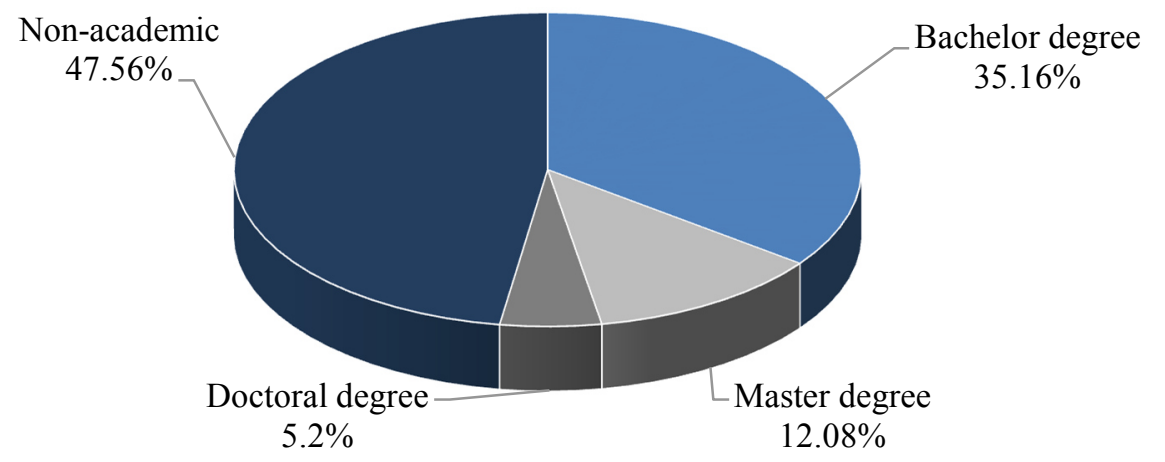

Figure 5 Percentage of international students coming to China in different academic degrees

\subsection{According to the Central Funding}

There were 63,041 Chinese Government Scholarship students, accounting for 12.81\%, meanwhile 429,144 selffunded students occupied $87.19 \%$. This shows that China is gaining more reputation overseas in terms education since it has a huge number of overseas enrolling in Chinese universities at their own cost. Which shows that over the years, China has attracted a lot intellectual talents under the BRI.

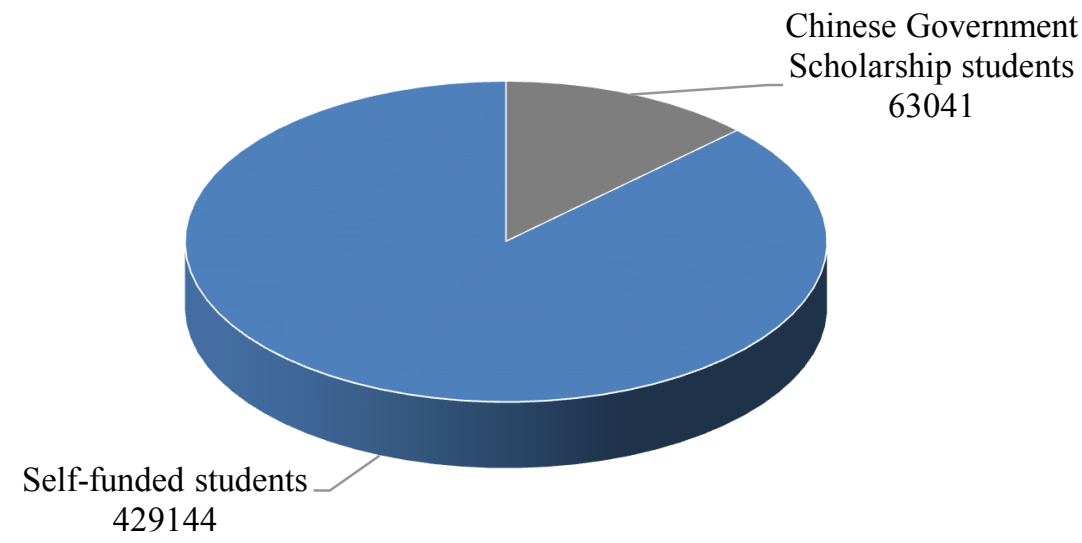

Figure 6 Number of international students coming to China in different financial resource

From Figure 6 we can conclude that more students are willing to come to China where they can acquire more 
knowledge and learn about Chinese culture. In addition, with the leading position of China, more talented are willing to relocate to China where they can grab many opportunities and a better living condition.

\section{Policy implementation to facilitate International Students' education under the BRI.}

\subsection{Expand language programs to attract more international student under the BRI}

Very few Chinese colleges and universities offer academic programs in the official languages of the Belt and Road countries, which affects the size and quality of the talent pool that China can tap into to connect with these countries. The Ministry of Education's Center for Research on Minority Languages must identify the main language regions of the belt and road countries and receive statistics on the non-universal languages that are essential for belt and road construction. It will also be important to collect data about foreign students from them villages.

It is argued here that once the major non-universal languages have been identified, colleges can recruit new teachers according to their faculty level, train teachers in the relevant languages, or send teachers to university to study the basics for the provision of educational programs in these non-universal base languages. Meanwhile, even Chinese universities can choose from excellent professors the universities of the Belt and Road countries; this would help to "import" the teaching methods of these countries into China, support international cooperation in education and exchange views with them countries and promote the teaching of major non-universal languages. It cannot only lead to the development of the talent pool that needs the BRI but will also attract more students from these countries to study in China (Zhao \& Chen, 2021).

\subsection{Combining the strategies to attract more international students}

The acceptance strategy is to increase the number of international students from Belt and Road countries and take full advantage of the 10,000 government scholarships for foreign students from these countries. When recruiting international students, Chinese universities should target students from Belt and Road countries and rationally plan and optimize educational programs for these students under the guidance of the BRI to strengthen disciplines closely related to the BRI. . However, given the differences between the Chinese education system and that of Belt and Road countries, Chinese universities should try to avoid a single model of education. Instead, they should implement a differentiated enrollment policy that offers specialized and academic levels targeting different countries based on the characteristics of their education system. In this way, China can cultivate international talents who understand and appreciate China, which will certainly be useful for the implementation of the BRI.

In addition to the strategy of attracting energetic students, the Chinese universities must also "run out". Chinese universities are required to send qualified talent to the Belt and Road countries in accordance with the BRI requirements and their own training programs. In this way, they can promote international exchange and cooperation in education, implement cross-border education vigorously, and bring forth an abundance of top-class talent to support BRIs. At the same time, Chinese universities can also work with high-quality companies in the Belt and Road countries to closel5y coordinate the training goals of talents with corresponding infrastructure projects of foreign companies, to promote education, translation universities and scientific research on business productivity, and to promote the social and economic benefits of international cooperation and communication.

\subsection{Diversification of Talents and Training}

To meet the academic needs and goals of international students from Belt and Road countries, Chinese universities need to move from the current model of unified university research to a diverse education system. Chinese universities should make the most of their strengths in the disciplines presented and Broad, diversified and application-oriented exchange and cooperation programs with Belt and Road countries. One outcome could be the integration of resources, as seen in international programs with joint degrees, or summer or winter program. The aim of such programs would be to attract more students from these countries for short-term studies and exchanges at Chinese universities expand the circle of potential foreign students and establish research and production collaborations between Chinese universities and related foreign companies. At the same time, some British and American universities have established overseas branches in China, such as the University of Nottingham Ningbo in China (a Sino-foreign cooperative university with independent legal status and jointly administered by the University of Nottingham, in the UK, and Zhejiang Wanli University in China).

\section{VI.Conclusion}

In the context of the BRI, the rapid development of Chinese education programs for overseas students from Belt and Road countries will help create a larger and better talent pool and intellectual confidence that can be used for further development and harmonious implementation of the BRI. In addition, such educational developments would stimulate cultural exchanges and educational cooperation between China and these countries and help promote China's educational and cultural diplomacy. Offer a broader and more specific education to foreign students from Belt and Road countries and create a larger pool of international interdisciplinary talents to support the implementation of the BRI. Chinese universities should actively respond to the inherent needs of the Chinese 
BRI, focus on working in non-universal base languages, integrate attractive strategies, and use diverse talent training models.

\section{Acknowledgements}

The authors would like to thank anonymous reviewers for their valuable comments. We also wish to thank the Overseas Education College and International office of Jiangsu University for their valuable support.

Foundation Items: Social Science Foundation of Jiangsu Province (17JYD002); Jiangsu Graduate Education and Teaching Reform Project (JGLX19_176); Special Project of "Double First-class" Construction and Internationalization of Higher Education of China Association of Higher Education (2019SYLZD09).

\section{References}

A. Peters, M., Oladele, O. M., Green, B., Samilo, A., Lv, H., Amina, L., . . Rulin, X. (2020). Education in and for the Belt and Road Initiative: The pedagogy of collective writing. Educational Philosophy and Theory, 52(10), 1040-1063.

Gholizadeh, A., Saneinia, S., \& Zhou, R. (2019). Belt and Road Initiative (BRI) as a Turning Point on China's Infrastructure Interconnection and Talent Exchange: Case of High-Speed Railway. Journal of Social and Political Sciences, 2(4).

Hillman, J. E. (2018). China's Belt and Road Initiative: five years later. Center for Strategic \& International Studies, 25.

Huang, Y. (2016). Understanding China's Belt \& Road initiative: motivation, framework and assessment. China Economic Review, 40, 314-321.

Hurley, J., Morris, S., \& Portelance, G. (2019). Examining the debt implications of the Belt and Road Initiative from a policy perspective. Journal of Infrastructure, Policy and Development, 3(1), 139-175.

JianQuan, M., Xuan, L., HongWei, W., \& YingJie, L. (2019). The Effectiveness and Problems of Talent Policy Implementation in China: Taking Major Talent Project as an Example. Paper presented at the 2019 Portland International Conference on Management of Engineering and Technology (PICMET).

Kirby, W., \& Van der Wende, M. (2019). The New Silk Road: implications for higher education in China and the West? Cambridge Journal of Regions, Economy and Society, 12(1), 127-144.

Li, C. (2021). Middle Class Shanghai: Reshaping US-China Engagement: Brookings Institution Press.

Li, M., \& Zhu, Z. (2019). Facilitating Cross-Cultural Communication: A Global Dimension to Fostering International Talents and Innovation in University Foreign Affairs Management Global Perspectives on Fostering Problem-Based Learning in Chinese Universities (pp. 244-272): IGI global.

Liu, W., Zhang, Y., \& Xiong, W. (2020). Financing the belt and road initiative. Eurasian Geography and Economics, 61(2), 137-145.

Ma, Q. (2019). Study on Economic Globalization and Accounting Internationalization. Paper presented at the 3rd International Conference on Culture, Education and Economic Development of Modern Society (ICCESE 2019).

Maçães, B. (2019). Belt and road: A Chinese world order: Oxford University Press.

Rolland, N. (2019). Beijing's response to the Belt and Road Initiative's "pushback": A story of assessment and adaptation. Asian Affairs, 50(2), 216-235.

Song, H., Varma, A., \& Zhang Zhang, Y. (2021). Motivational cultural intelligence and expatriate talent adjustment: an exploratory study of the moderation effects of cultural distance. The International Journal of Human Resource Management, 1-25.

Song, T., Liu, W., Liu, Z., \& Wuzhati, Y. (2019). Policy mobilities and the China model: Pairing aid policy in Xinjiang. Sustainability, 11(13), 3496.

Wang, Y., \& Xin, L. (2020). The impact of China's trade with economies participating in the Belt and Road Initiative on the ecological total factor energy efficiency of China's logistics industry. Journal of Cleaner Production, 276, 124196.

Xinchun, W., Weibin, L., \& Yanli, M. (2020). Foreign Language Teaching at College Level in China Under the Background of the Belt and Road Initiative. Paper presented at the proceedings of the 2nd International Conference on Literature, Art and Human Development (ICLAHD 2020).

Zhang, X. (2021). Strengthen the "Unimpeded Trade" Between China and Russia and Share the Digital Economy. Paper presented at the XV International Conference" Russian Regions in the Focus of Changes"(ICRRFC 2020).

Zhao, X., \& Chen, S. (2021). Research on the Normalized Online Teaching Strategies of Ordinary Universities in the Post-Epidemic Era. Paper presented at the 2021 International Conference on Modern Education and Humanities Science (ICMEHS 2021).

Zheng, W. (2019). An "Embedded" Mode of International Talent Training Boosts the Two-Way Opening of Higher Education. Open Journal of Social Sciences, 7(03), 136. 
Zhu, L., \& Chen, Y. (2019). Dovetailing the Belt and Road Initiative with the 2030 Agenda for Sustainable Development: The Connotations, Objectives and Pathways. Chinese Journal of Urban and Environmental Studies, 7(01), 1940005. 